Newcomers, betweenness centrality, and creative success:

A study of teams in the board game industry from 1951-2017

\author{
Mark Lutter \\ University of Wuppertal \\ Gaußstr. 20, 42119 Wuppertal, Germany \\ Phone: +492024392168 \\ lutter@uni-wuppertal.de \\ Linus Weidner (corresponding author) \\ University of Wuppertal \\ Gaußstr. 20, 42119 Wuppertal, Germany \\ Phone: +49 1734938074 \\ weidner@uni-wuppertal.de
}

This version: Jan 12, 2021 


\title{
Newcomers, betweenness centrality, and creative success: A study of teams in the board game industry from 1951-2017
}

\begin{abstract}
This study examines how network characteristics affect the creative success of teams in the board game industry. Based on prior research, we argue that the degree of newcomers within a team affects the creative success negatively, while betweenness centrality affects creative team success positively. We test these assumptions with unique data on teams in the board game industry using two different measures of creative success (awards as well as user- ratings). The data covers 12,731 teams over a timeframe from 1951-2017. Results indicate moderately curvilinear effects of betweenness centrality as well as negative effects of the number of newcomers per team on creative success, suggesting that creativity is not only driven by network diversity, but also by trust and experience. This paper contributes to a better understanding of team-based creativity which also validates and expands on the prior knowledge of network-based origins of creativity in an industry-setting that has never been studied before.
\end{abstract}

Keywords: Board games, betweenness centrality, creativity, networks, network analysis, newcomer, 


\section{Introduction}

Explaining creative success of teams has gained a lot of attention from social network research in recent years. Originating from the works of Granovetter (1983) and Burt (1992), studies look at how weak or strong ties, core/periphery structures, or brokers bridging structural holes affect the generation of innovative ideas, and ultimately, creativity and creative success (Burt, 2004; Cattani \& Ferriani, 2008; Perry-Smith, 2006; Perry-Smith \& Shalley, 2003; Uzzi \& Spiro, 2005).

A central finding from these studies is that the level of network centrality affects creativity in a positive way. Teams that include actors who bridge otherwise distant actors or clusters outside the team bring in new ideas, which positively affects the creative success of those teams. Research also suggests that newcomers within a team bring in fresh or unorthodox ideas, and that these ideas are also beneficial for the creative process (De Vaan et al., 2015; Perretti \& Negro, 2007). Generally, it seems that team-based creativity is not only a characteristic of the talents of the individual team members, but to some degree is rooted in the specific social network structure of the teams. These findings therefore point to the social origins, or the "social embeddedness" (Granovetter, 1985), of valuation outcomes in social and economic life.

In this study, we build on this knowledge, and examine whether betweenness centrality of creative teams as well as their number of newcomers affect their creative success. While prior research so far has looked at relatively large teams on average, we look at an industry where teams are typically small. In doing so, we focus on a comprehensive dataset that draws on a total of 12,731 developer teams in the board game industry, a creative field that has not been studied from a network perspective (but see Wachs \& Vedres 2021 for an analysis on crowdfunding and innovation). The board game industry is in many ways comparable to other creative domains that have been studied previously, such as the Hollywood movie industry or the video game industry (Cattani \& Ferriani, 2008; De Vaan et al., 2015; Lutter, 2014). It is a 
project-based industry involving short-term projects (Bielby \& Bielby, 1999; Faulkner \& Anderson, 1987), in which a team comes together with the task to develop a game. After completing the project, each team member goes their own way and seeks employment in other projects within that industry.

In contrast to movies or video games, board games have been around for thousands of years. Some games such as chess or go have stood the test of time and are still played in many parts of the world, while others, such as the game of the goose, which was famous in the middle-ages (Seville, 2009, p. 1001), have lost their appeal. Most ancient games are competitive in nature and are abstract designs. Some of them are quite complex, ${ }^{1}$ and much time has to be invested to become a versed player. The sheer scope of possible options in these games provided a great challenge for AI until recently (Silver et al., 2018). Modern games are often much less complex, but much more thematic. This is also fostered by much more elaborate designs. One of the first of these modern games reaching global commercial success is the game Monopoly (Whitehill, 1999, p. 131f.). It was first published by a big company (Parker Bros.) in 1934, but has been sold before and builds on a predecessor called The Landlord’s Game, which was invented in 1904 (ibid.). Games copying gameplay mechanism, or in some cases even the main theme of previous games is common in the industry today. With over 100 million copies sold by 1999 (ibid.) "Monopoly went on to become the most popular proprietary game in the world" (ibid. p. 133). The theme of the game is pretty straightforward - it is all about making money. Since then, the offerings have become much more plentiful and diversified with regards to theme, gameplay, design, and also the way the games are marketed. According to multiple sources, ${ }^{2}$ the industry was valued at around USD 12 billion in 2018, forecasting further growth. While early games mostly tried

\footnotetext{
${ }^{1}$ Not to be mistaken for "complicated", which means that the game has a lot of rules to it.

2 https://www.grandviewresearch.com/industry-analysis/playing-cards-board-games-market (last access: Oct 26, 2020).

https://www.statista.com/statistics/1072042/global-card-and-board-games-market-value/ (last access: Oct 26, 2020).
} 
to fulfill a secondary function such as educating the players or conveying moral values, modern board gaming is primarily about fun (ibid. p. 139f). The definition of fun obviously varies from person to person. While some enjoy the competitive aspect of gaming, “(m)any recent game designs feature balanced combinations of cooperative and competitive game mechanisms" (Zagal et al., 2006, p. 27). Some games such as Mansions of Madness: Second Edition, or Detective: A Modern Crime Board Game even require an accompanying digital App to enjoy the full experience, crossing the line between video- and board gaming. Another recent trend has been the introduction of so-called "legacy" systems. Games such as Pandemic Legacy: Season 1 or Gloomhaven come with a lot of sealed content, which is unlocked by the players over successive plays of the game, keeping the experience fresh and interesting for a longer time span. These games might provide the most thematic experience, but require a much more dedicated group of players to reach the end of the story line. This story can be told over almost 100 individual sessions in the case of Gloomhaven for example. Other, simpler designs, such as family games or so-called party games, are also very popular. It should be evident, that these games require a very different approach from their developers. Therefore, many developers and publishers specialize in certain types of games. A good example is the publisher GMT Games ${ }^{3}$ who specializes in war games, adding strategy games, eurogames ${ }^{4}$ and family games to the portfolio. They also make use of crowdfunding in order to reduce the financial risk that goes along with the production of board games. More and more developers are also trying to finance their projects via crowdfunding directly, 5 bypassing the publishers completely. Nevertheless, publishing companies still dominate the

\footnotetext{
${ }^{3}$ https://www.gmtgames.com/t-about.aspx (last access: Oct 28, 2020).

${ }^{4}$ The term describes games that are less luck based and often times less thematic, focusing on the gameplay mechanics instead.

See https://boardgamegeek.com/wiki/page/Eurogame (last access: Oct 28, 2020).

${ }^{5}$ See https://www.kickstarter.com/discover/categories/games/tabletop\%20games?lang=de (last access: Oct 27, 2020).
} 
mainstream market for board games, with big players such as Asmodee selling over 34 million games in 2018.6

Board games are not always created by single developers, but often the result of a team effort. In contrast to most other project-based creative industries, however, the field of board-game developing consists of much smaller teams than, for instance, video game or movie film production. For film production, Cattani \& Ferriani (2008, p. 830) report core teams which range from 12 to 15 on average, depending on the year. De Vaan et al. (2015, p. 1168), who examine the video-game industry, observe a mean team size of about 41 ( $\mathrm{SD}=46.63)$. Teams in the board game industry on average consist of two or three members only. $50 \%$ of teams have less than two, 75\% have less than three, and $90 \%$ have less than four team members (based on estimates of the data we present below). This specificity enables us to test previous findings in a different environment in terms of team size; it also enables us to assess whether the assumption that betweenness centrality and newcomers affect team-based creativity positively still holds true in other areas and for different team structures.

In contrast to prior studies, we argue that betweenness impacts creative success positively, but that having many newcomers within the team is less beneficial in a small-team industry. Moreover, we show that betweenness centrality is especially advantageous in teams without any newcomers. This result points to the idea of "structural folding” (Vedres \& Stark, 2010), namely, that the beneficial bridging effect that is reflected in the concept of betweenness centrality works best if the team consists of a set of experienced and familiar actors who probably know how to exploit their beneficial bridging position within the network of their industry. If creative groups want to exploit diverse network structures successfully, they need to integrate that within an experienced team who is able to handle new information in a productive way.

\footnotetext{
${ }^{6}$ https://corporate.asmodee.com/ (last access: Oct 27, 2020).
} 


\section{Creativity and network characteristics: theory and hypotheses}

In sociology, creativity is seen as a result of social interaction (Accominotti, 2009; Perry-Smith \& Shalley, 2003). Creative ideas are generated when people share different inputs and reassemble them in new ways. Such an input can be an idea, knowledge, or even certain views or values. Csikszentmihalyi (1996, p. 23) describes this as follows: “Creativity does not happen inside people's heads, but in the interaction between a person's thoughts and a sociocultural context.” Csikszentmihalyi (2009) suggests a theoretical model of creativity, which Sawyer (2010) calls a "sociocultural approach" to creativity. In this approach a group experiences most creativity when it is neither too divided nor too uniform. "Ideal conditions for creativity would be a social system that is highly differentiated into specialized fields and roles, yet is held together by what 'Durkheim ([1912] 1967)' called the bonds of "organic solidarity” (Csikszentmihalyi, 2009, p. 323f).

This approach is similar to what Uzzi \& Spiro (2005) call the "small world approach" to creativity. They analyzed creative teams in the Broadway musical industry and showed that the small worldliness of the network, which is described as short average paths lengths combined with many densely-connected clusters, predicts creative success in an inversely ushaped manner (ibid., p. 453). This means that creative success is highest if there is neither too little nor too much small worldliness.

A similar approach of network analysis is the idea that highly creative networks imply a core and periphery structure. An attempt to formalize these concepts mathematically has been made by Borgatti \& Everett (2000). Cattani \& Ferriani (2008, p. 836) analyze such structures with regard to creativity. They find an inverted u-shape relation between coreness and creative performance. In other words, people who occupy an intermediate position between core and periphery are most likely to be highly creative. Again, there is a nonlinear relationship to that, i.e. creative success is highest if there is neither too much nor too little coreness in the team. According to this study, these results even apply to the individual's 
career level. Other authors also note that creative artists tend to become more and more central until creativity is affected negatively again (Perry-Smith \& Shalley, 2003).

Based on these theoretical considerations, we hypothesize that in the board game industry, creative success depends on the degree to which teams are able to connect to otherwise distant groups. One of the most straightforward concepts of this bridging function is the concept of betweenness centrality. If a team has high levels of betweenness centrality, many shortest paths in the overall network move through that that team. High betweenness therefore brings non-redundant ideas into the team, which are fruitful for the creative process. Betweenness is therefore a more adequate measure than coreness or any other network characteristics to capture the flow of information/ideas through the network. A potential alternative is the concept of structural holes (Burt, 1992). Nevertheless, we consider betweenness to be of greater explanatory value for the present data set, as it is a global measure of information flow and accessibility of that information, rather than a local measure that only pinpoints specific extremely important nodes. This focus on a more global measure is explained by certain industry characteristics. Most teams in the board game industry are small and many game developers do not make a living from their board game creations. Hence, a focus on the few outstanding games, or star developers would not reflect the underlying network very well.

We have no reason to assume that the inversely u-shaped relationship between coreness as a related concept (Cattani \& Ferriani, 2008, p. 836) and centrality (Perry-Smith \& Shalley, 2003) is any different in the present sample of board games or for betweenness centrality specifically. Hence, the relationship is likely to be nonlinear, i.e., betweenness centrality positively affects creative success up to a certain point, after which its positive impact starts to decline. The decline at high levels of betweenness is likely, because the possible flow of information through any node can become too much too handle. Or expressed differently, if a team connects many shortest paths in the network, an information overload might occur. This can be either a problem of limited cognitive capacity of the individual team members (for 
example by memory capacity), or a failure to aggregate the information in meaningful ways at the team level. In both cases, the inversely u-shaped effect of betweenness on creative performance should be observable.

H1: The higher a team's degree of betweenness centrality, the higher its creative success. Betweenness centrality is positively related to creative success, but in an inversely u-shaped relationship.

Another focus of prior sociological research on creativity has been the role of newcomers within the team. One strand of research argues that newcomers are beneficial for the creative process (De Vaan et al., 2015; Perretti \& Negro, 2006, 2007). One reason for this is that newcomers bring in fresh and novel ideas into the group. Their unorthodox way of thinking generates friction with those who have more traditional or established ideas. This dissonance has the potential to produce new, innovative concepts which are important for the creative success of the team (Stark, 2009). In organizational theory, this is often thought of as a dynamic of exploitation vs. exploration, i.e., re-arranging old ideas (exploration) with new perspectives (exploitation) (March, 1991). Another related reason for why newcomers are beneficial for the creative team is that newcomers maintain different network ties outside the established industry. As newcomers, they naturally hold network ties to other newcomers in the industry or to complete outsiders of the field. Therefore, these ties can be very beneficial as they bridge structural information holes (Burt 1992, 2004), which leads to different, nonredundant information pools.

Accordingly, De Vaan et al. (2015, p. 1177) find that newcomers positively affect creative team performance in the video game industry. Perretti \& Negro (2007, p. 574) conclude from their research that teams who contain both newcomers and old-timers at the same time achieve the highest rate of genre innovation in the Hollywood movie industry. They also show that teams with either high or low status are more likely to incorporate newcomers compared to those with a medium status (Perretti \& Negro, 2006). Similarly, 
Gilson \& Shalley (2004, p. 466) find evidence that a moderate amount of organizational tenure leads to the most creativity within the team.

However, while positive effects might arise because newcomers contribute to new and different ideas, there is research that emphasizes the negative aspects of newcomers. First, newcomers tend to underperform in comparison with their more experienced peers (Quińones et al., 1995; Schmidt \& Hunter, 1998). Second, newcomers increase the demographic diversity of the team. Research suggests that demographic diversity has the potential to trigger coordination problems; it likely intensifies polarization dynamics between in-groups and outgroups, leading to emotional conflict and reduced levels of communication (Hogg \& Terry, 2000; Hornsey \& Hogg, 2000; Montoya \& Horton, 2013). This potentially dampens the creative process. Accordingly, some research on creativity finds negative effects of newcomers on the individual's creative success (Lutter, 2014, p. 14). These dynamics are potentially severe in small teams because dynamics of polarization can lead to severe underperformance or even a complete dysfunction of the team. Therefore, we hypothesize that newcomers in the board game industry have rather negative than positive effects on the creative process.

H2: The higher a team's number of newcomers, the lower its creative success.

\section{Data and methods}

\section{Data source and preparation}

The data for the present study was collected with a web crawler that scanned html elements from the boardgamegeek.com database. ${ }^{7}$ Boardgamegeek (BGG) is a community-run encyclopedia of almost all board games and the relevant information related to them. Moreover, the site serves as a trading platform for board games. The term board game is understood in a broad sense as dice games, card games, tile-laying games, dexterity games as 
well as many more are included. Currently, the database contains information on more than 100,000 board games. All community members can edit and upload information on any particular game. In that sense, BGG works similarly to other well-known community-run websites like $\mathrm{IMDB}^{8}$ or Wikipedia. Brand new entries (publishers, games or virtual persons) have to be approved by the administrators of the site.

Once we collected all the data, the resulting dataset contained many so-called 'expansions'. These games are not playable standalone, and require a main game to be played with. Many of them are no new inventions in a creative sense, but rather add a few new mechanics to an existing game. Therefore, we decided not to include them in our analysis. We also excluded all games that had missing data on any of the main variables that were relevant for the network structure (developers, year published). Moreover, we excluded all games that were developed before the year $1951^{9}$ and pre-release versions. Most of the games in the database have been developed after 1951; therefore, including the older games would result in large time gaps.

Some games are labeled as "reimplements" according to BGG. These are neither expansions nor simple re-issues ${ }^{10}$. A good example of a reimplemented game would be Monopoly Star Wars. These types of games usually incorporate some creative innovation and are playable without the original game; hence, we included them in our analysis. In the models below we control for reimplements since consumers or game critics might perceive them more favorably.

For most of the games at least one 'designer' and one 'artist' have been involved in the production. A designer is typically responsible for the conceptual elements whereas an artist

\footnotetext{
${ }^{8}$ https://www.imdb.com (last access: April 7, 2020).

${ }^{9}$ Most of the games before 1950 contained no information on the developers. Therefore, we decided to start our analysis from the year 1951 onwards instead.

10 Simple reissues are labeled as 'version' on BGG. We only considered primary versions when collecting the data. Moreover, BGG contains information on some game compendiums/compilations/collections. These are games which contain additional contents or boxes that contain multiple games. As community members cannot rate them and they usually do not win any awards, they are also not included in our analysis.
} 
is primarily in charge of the representation/design choices. We treat artists and designers as being equal in the sense that both have the same chance to be more or less creative in developing the game. Whether conceptual creativity should be valued over artistic creativity, or the other way around and what tends to affect the appreciation of the final product is not the focus of this study. The main dataset contains 12,731 board games which were released between 1951 and 2017.11

\section{Structure of the bipartite network dataset}

In order to calculate our main network measure (betweenness centrality, see below), we generate a complete bipartite network from the main dataset. Networks are mostly structured as one-mode networks, with "one set of nodes that are similar to each other“ (Opsahl, 2013, p. 159). A two-mode network, such as ours, contains two different sorts of entities instead. Such networks are also referred to as bipartite or affiliation networks. An example of this structure is a scientific collaboration network (Mizruchi, 1996). There, one node set contains the researchers, while the other contains the papers that have been published by these researchers. Other examples are event attendance networks or networks of corporate boards and directors (Opsahl, 2013, p. 159).

In this study, the first set of nodes contains the board games, while the second set contains the developers. We also refer to the games as teams (of developers), depending on the context. In a two-mode network structure, ties can only exist between nodes from different node sets. If we transfer this to our data, it means that direct ties can only exist between the games/teams and the corresponding developers. A game is linked to every developer who contributed to its creation, and vice-versa. The network is therefore undirected, as the edges

\footnotetext{
11 Although there is a time component here (release date of the game), it is important to note that this data structure is not a panel dataset. Each row in this data constitutes just one specific game (with a specific release date), while each column contains specific variables such as release year, betweenness centrality, and so on. Therefore, panel data methods such as fixed-effects regression or panel-specific clustering of standard errors are not possible here.
} 
(links/ties between nodes) are bidirectional. Multiple ties are present between some nodes. They occur when a person is both the designer and the artist for the same game. These ties have been merged, so that all ties in the network have a strength/value of one. This means that the ties in the network are not weighted, which would require an even more sophisticated approach.

Each node and every edge is also specified by a time component. For every game, the year of its release states its first appearance within the network. The same holds true for its ties to the corresponding developers. The developers, on the other hand, enter the network in the year when their first game was released.

Indirect connections between games or developers are of course possible via the other node set, i.e. developers that are connected by working on the same game or games that are connected by sharing a common developer. In order to analyze these indirect ties, two-mode networks are often converted into a one-mode network by a process called projection (Opsahl, 2013, p. 159) ${ }^{12}$. Another reason for this approach is the fact that many network measures have been developed for one-mode networks, while two-mode measures are still rare. As we are specifically interested in the way in which both node sets (teams/developers) interact, and a good betweenness measure for bipartite data is available (Borgatti, 2009), we do not use any projection methods and keep the network in its original two-mode structure.

The network dataset contains 12,731 games and 12,502 developers. Figure 1 shows the distribution of nodes (games/developers) and ties (connections between nodes) in the network by year. As illustrated, the board game industry has grown steadily since 1951. Table 1 provides an overview on all variables used in this study. See also Table A1 for a correlation matrix as well as Table A2 for variance inflation factors (based on the full regression model,

\footnotetext{
12 Nevertheless, the resulting network would be structurally different from original 1-mode data (Opsahl, 2013, p. 159f).
} 
Model 5 in Table 2). As can be seen, there is no problematic multicolinearity among the variables. We describe them in detail in the next section.

$<$ Figure 1 about here $>$

$<$ Table 1 about here $>$

\section{Dependent variables}

In accordance with previous work, we use two measures of creative success, awards and ratings. While the number of awards received measures critical creative success (expert level), ratings are user votes and measure public creative success (consumer level). With regard to our first dependent variable, number of awards, we decided to count not only the awards but also the award nominations. Cattani \& Ferriani (2008) as well as Rossman et al. (2010) and Lutter (2015) also include award nominations since being selected and nominated is already a form of creative success. There is no reason to assume that this would be any different in the board game industry, hence, we treat every award and nomination as being equal. A total of 2,861 games (22\%) received at least one award or nomination, while the majority of 9,870 games received no award or nomination.

As for the second dependent variable, rating, we use the internal BGG rating. This is used instead of the simple average rating because it considers the number of votes as well. Each registered user can assign a rating to any game he/she likes on a non-integer scale ranging from 1 to $10^{13}$. The specific values of the algorithm used for the calculation of the BGG rating are not available to the public to avoid manipulation but its calculation is fully explained. In order to prevent games with only a few ratings from climbing to the top of the rating charts, an artificial dummy vote is added to the average user rating. As a rough estimation, this dummy can be thought of as 100 votes to the midrange of the voting scale at

\footnotetext{
13 For the statistical analysis we scaled these values up by a factor of 100.
} 
around 5.5 out of $10 .{ }^{14}$ This process is also known as Bayesian averaging. Later on in the lifecycle of the site, this process was slightly tweaked in order to account for community growth. Nowadays, the amount of dummy votes that are added to the calculation is no longer fixed, but depends on the overall amount of votes conducted by all community members. ${ }^{15}$ Because of this calculation, games with only a few ratings tend to achieve a rating closer to the average of the scale, whereas games with a lot of ratings get a BGG rating close to their real average. The calculated BGG rating and the corresponding ranking of a game is only shown for games where the number of votes is $>30$. This is plausible since several cases are needed in order to get anything close to a true value from a statistical point of view. In addition, the Bayesian averaging would be overly harsh if games with very few votes would be considered. Therefore, we also decided to include only those games with at least 30 votes in our analysis.

\section{Predictors}

In order to test $\mathrm{H} 1$, we calculate the two-mode betweenness centrality for each team from the network dataset and apply that information to each board game in the main dataset for the final analysis. Borgatti and Everett define betweenness centrality as follows: "Betweenness may be roughly defined as the number of geodesic paths that pass through a given node, weighted inversely by the total number of equivalent paths between the same two nodes, including those that do not pass through the given node” (Borgatti \& Everett, 1997, p. 256).

In the present study, we calculate betweenness centrality based on Borgatti (2009, p. 8287). Betweenness centrality of a team reflects the sum of the fraction of all-pairs shortest paths that pass through the team (see equation 1 in appendix B for details). A shortest network path between any two nodes in the network can be a path from a developer to another team,

\footnotetext{
14 https://boardgamegeek.com/wiki/page/BoardGameGeek_FAQ\#toc4 (last access: Nov. 7, 2020).

15 https://www.boardgamegeek.com/thread/103639/new-game-ranking-system (last access: Nov 7, 2020).
} 
between two developers, or between two teams. If such a path goes through the focal team, its betweenness value increases. The maximum number of ties for any node in a bipartite network is limited by the number of nodes in the opposing node set (Borgatti \& Halgin, 2014, p. 427). Hence, we normalize the measure accordingly (see equation 2 in appendix B). This implies that ties are only considered if they are at least two steps away from the focal team. In other words, ties among team members of the focal team are not considered in the calculation of the betweenness measure.

Except for the normalization of the measure, the two-mode betweenness is similar to its one-mode counterpart. We calculate this measure using a three-, five-, and ten-year window. For three-year betweenness centrality, for example, the measure captures all nodes/ties in the network in the focal year of the development of a game and the nodes/ties from the previous two years. We do not find substantial differences between the three versions. Hence, the results presented below use the three-year version (see Table A4 for results for the five- and ten-year version). Finally, the measure is divided by the team size in order to take into account that larger teams are more likely to obtain higher betweenness scores.

On a substantial level, the betweenness measure captures the degree to which a team has "fast" or short access to diverse sources of information outside of its immediate reach, i.e. outside of the information/knowledge that the team members already possess. Higher betweenness values indicate that more shortest paths move through the focal team, making it more likely that different information or ideas reach the team. Lower values on the betweenness measure indicate that less shortest paths move through the team, making it more likely that diverse information passes through other network paths. A value of zero means that the team is not contributing any shortest paths to the overall network. This is frequently the case if a game has been developed by a single person, who has not worked in any other conjoint project during that time window. 
In order to assess our second hypothesis, we calculate the number and the proportion of newcomers for every game by sorting the games by developers and extracting their first time appearances in the network. The total number of newcomers is therefore equal to the total number of developers since every person has made a debut game. Afterwards, we add up the newcomers for every game and divide the resulting score by the team size to calculate the proportion of newcomers. Almost half of the games had no newcomers in their corresponding teams $(\mathrm{N}=6,188)$, which means for slightly over $50 \%$ of the games at least one newcomer was present during the production process $(\mathrm{N}=6,543)$. We use this measure as a continuous variable, but also as a dummy-coded measure (see below).

\section{Controls}

We use the following set of control variables Time. In order to examine general time trends over a large timespan, we use a time trend measure that we calculate as the number of years from the first year of the analysis onwards. The variable is log transformed to control for diminishing marginal effects and skewness. Because more awards are available nowadays, we expect a positive effect of this variable. When using year dummies instead of a continuous (logged) variable, the results remain unaffected (see Table A4, Models 5 and 6).

Team size. This variable examines the size of the team. It is important to include this particular control since larger teams might have both more newcomers as well as more beneficial network ties. In addition, team size is also a measure for "how much" human capital is involved in the development of the game. In the models we enter this variable in its $\log$ form to account for skewness.

Experience. This variable calculates the prior experience for every team. To compute this measure, we count all prior projects from all years for every developer in a focal team, and accumulate to the team level. To account for simultaneity bias, we then subtract all individual projects from the focal year to get a value based solely on prior work. Finally, we 
adjust this measure by team size. This control allows us to separate network effects (betweenness) from mere learning through experience. Experience is also known to affect reputation (Jensen \& Kim, 2020, p. 2), which makes it even more valuable as a control. Moreover, experience is a key part of the newcomer variable central to this study. The unique characteristic of a newcomer is an experience of zero. Nevertheless, the concepts are clearly distinguishable, which can also be seen by the low correlation of the two (see Table A1). We expect a positive relationship between experience and both measures of creative success.

Difficulty. Another control variable we take into consideration is the perceived difficulty of a game. Difficulty might have an impact on the creative success of a game because games which are too easy to learn or play are sometimes considered as less innovative enough to warrant a prize. Games have to have a certain level of difficulty in order to receive critical attention. We calculate the measure from subjective scores of users that the BGG database provides. The average user of the BGG database is probably more of an expert on board games and might not be representative of the industry's mass market. Therefore, a tendency to favor difficult games disproportionally in relation to more entry-level/familyfriendly games might exist in the BGG community. The complexity score is a user-assigned rating on an integer scale of 1-5. The overall complexity score is then averaged over all votes and reported on a non-integer scale. Unfortunately, some games have not been assigned any complexity ratings, which leads to missing data on the variable for 192 cases. We enter this variable in its log form to account for diminishing effects of game difficulty.

Reimplements. In order to examine games that are in some respect successors of previous ones, we calculated a dichotomized dummy variable called reimplements. As mentioned above, reimplements usually incorporate some creative innovation and are playable without the original game. Out of the 12,731 games, 1,263 (9.9 \%) were classified as such. Regarding the number of received or nominated awards, we expect a negative effect of reimplemented games. The reason is that the first game of this kind is probably most likely to 
be seen as the main innovation. Regarding the rating variable, positive as well as negative relationships are possible. Since most reimplemented games already have a profound fan base, reimplementations will probably achieve relatively high ratings most of the time. Nevertheless, the community might perceive some reimplements less favorably. They may be regarded merely as a commercial spin-off, and are therefore voted down. Often it is also the case that its announcement raises expectations due to the success of the previous game; however, high expectations are difficult to satisfy and are much more likely to be a disappointment in which case the ratings would drop.

\section{Results}

Table 2 presents a series of OLS regression results for the first dependent variable (awards); Table 3 presents the results for the second dependent variable (rating). The first two models of both tables include one predictor variable each plus the time trend control. Models 3 and 4 then enter the full set of controls for both predictors separately. Model 5 shows the full model that includes all controls plus both predictors simultaneously. Model 6, finally, enters the dependent variable in its logged form. In order to test the nonlinear prediction in hypothesis H1, the betweenness variables enters with a squared term in all models.

$<$ Table 2 about here $>$

$<$ Table 3 about here $>$

Regarding H1, all models consistently show a positive, nonlinear effect of the betweenness variable on both dependent variables. The negative squared term suggests an inversely u-shaped relationship. This means that betweenness of teams is generally beneficial for the creative success (on both levels, critical success as well as the consumer ratings), but with a diminishing reward toward higher values of the betweenness distribution. The nonlinearity of the effect is relatively small, however, as the graphical representation of the effect shows (see Figure 2). In both figures, the positive effect starts to decline at a 
betweenness value of approximately .01, which is far beyond the average. It means that for those teams which have values on the betweenness measure higher than the upper 1\%-decile, the effects start to become negative. For the majority of the teams, the betweenness effect is rather a positive-linear effect.

$<$ Figure 2 about here $>$

Regarding H2, the results consistently show that the newcomer effect is negatively associated with creative success, again for both dimensions of creative success. The full model in Table 2 (Model 5) shows that if the percentage of newcomers per team increases by one, the expected number of awards decreases by .151 on average, or by about $5 \%$, as shown by the log-lin model in column 6 . The same holds true for the rating variable. If the percentage of newcomers increases by one, the average rating declines by about 46 points (Model 5 in Table 2), or by about 7\% (Model 6 in Table 2).

Table 4 presents a few alternative specifications. Models 1 to 3 replicate the full covariate model using logistic regression on the two dependent variables transformed to binary dummies. Model 1 estimates the likelihood of receiving any award or nomination; Model 2 estimates the likelihood of being in the top-25\%-percentile of the highest rated games; Model 3 examines the likelihood of being the top-10\%-percentile of the highest ratings. Comparing all three models, the betweenness- as well as the newcomer-effect is especially pronounced for the top $10 \%$ rating games.

$<$ Table 4 about here>

Model 4 and 5 further explore interaction effects between newcomers and the betweenness variable on their effect on the number of awards (Model 4) and on ratings (Model 5). Both models find a positive interaction effect, however, with only the second one being meaningfully statistically significant. Figure 3 displays both effects graphically. Especially for ratings (figure to the right), teams with higher percentages of newcomers benefit much more from team-level betweenness than teams with lower percentages of 
newcomers. It seems that the beneficial network structure that comes with high levels of betweenness can be best transformed into creatively beneficial social capital when the team also integrates a higher amount of newcomers.

$<$ Figure 3 about here $>$

Before we conclude, we briefly discuss the main results of the covariates. Generally, we see that the main effects are unaffected by the additional controls. When including the full set of controls in Models 4 to 6 in Tables 2 and 3, we see that larger teams outperform the smaller ones both in terms of awards as well as ratings. The likelihood of receiving awards or high ratings also increases over time. The positive time trend might be explained by the fact that board games have gained a lot of popularity over recent years (see Figure 1) and the number of awards distributed overall have also increased noticeably. The experience of a team is positively related to both awards and ratings. It seems that teams with higher amounts of human capital can transform this into creative success. Creative success is also significantly higher for those games which are more difficult. Due to the fact that the juries who decide what games get nominated for an award are experts on board games themselves, they seem to favor games which are somewhat more challenging than those games which are more oriented toward kids/families or casual gamers, even if these games are likely to sell more copies to the target audience. Whether a game is a sequel to a predecessor or not seems to have no significant effect on received awards, since the reimplements variable is not significant in Table 2. On ratings, however, reimplements have a significant effect. This result might be explained by the fact that many games have a loyal fan base of people who are more likely to assign higher ratings to reimplementations of their favorite game. Therefore, reimplements are not rewarded by the critics, but are evaluated positively by the consumer. 


\section{Conclusions}

Most of the previous studies that have looked at creativity from a social network perspective either focus on career paths at the individual level or have analyzed large teams (Cattani \& Ferriani, 2008; De Vaan et al., 2015). This study examined whether previous findings are also relatable to a creative industry dominated by much smaller teams. Focusing on the effects of newcomers and betweenness centrality on the creative success of teams in the board game industry, we partly confirm, and partly disconfirm prior research results.

According to our results, betweenness centrality relates positively to creative success. This is in line with much prior research on other creative domians (Cattani \& Ferriani, 2008; Uzzi \& Spiro, 2005). Teams that provide short/quick connections between other nodes show higher levels of creative success. This also indicates that teams that bridge structural holes and are able to connect to otherwise distant groups benefit from non-redundant ideas, which ultimately benefits the creative process. The effect of betweenness centrality on creative success is moderately inversely-u-shaped. While for the bulk of teams, betweenness centrality relates to creative success almost in a linear-positive manner, it is only for teams with betweenness levels that are extremely far beyond the average that the effect starts to become nonlinear. This may be explained by the sheer amount of information that causes a lot of cognitive load for the team members or by a failure to aggregate the information creatively at the team-level. These teams are possibly too diverse and lack an element of trust that is necessary for the flow of ideas within the team. The ideas that come into the team may be non-redundant in those teams. But these highly diverse teams may lack trustworthiness that reduces sharing or the communication of these ideas. The lack of "structural folding" (Vedres \& Stark, 2010) may be what drops the creative success of those teams. We want to make clear, that this is only a potential explanation which needs to be elaborated further in future research. 
In sum, the results support the argument for the positive influence of diversity on creativity as far as network diversity through betweenness centrality is concerned. In regards to the level of newcomers however, it seems that this kind of diversity is detrimental for the creative process. Contrary to prior research on newcomers (De Vaan et al., 2015), we find that teams with newcomers show lower rates of creative success, both at the expert as well as the consumer level. This rather confirms studies that point to the negative aspects on some parts of diversity (Hogg \& Terry, 2000; Hornsey \& Hogg, 2000; Montoya \& Horton, 2013). Diversity may not only lead to new input but can also create problems of coordination within the team, and thus, can intensify conflicts between in- and outgroups. This has the potential to reduce levels of trust and communication among the members of a team. Nevertheless, the fact that we find a linear negative relationship between the percentage of newcomers in a team and both measures of creative performance might be an artifact of the underlying data structure. As teams are very small on average, the negative effects of newcomers could be more pronounced in the present data compared to other creative industries. From a statistical point of view, the small team size also makes it difficult to identify any non-linear relationships.

Even though further study on this topic is required, the effect of betweenness centrality on creativity seems to be generalizable across industries. We can conclude from the results that small teams and large teams function in comparable ways when the optimal composition for creative work is considered. This is also an important implication for managerial work and team assembly in creative industries (Guimerà et al., 2005).

Because the present study uses data from a community-run website, possible limitations may concern the quality of the data in terms of any missing, unobserved data. The data contains only released games; therefore, games that have been developed but have never seen the light of day in terms of an official release are unknown to the public. The teams behind such games may have different network characteristics that we cannot observe. This 
may be related to the variables in our study, which would mean that a possible success bias could not be ruled out completely. However, this also creates avenues for future research. It would be interesting to compare projects with successful and unsuccessful outcomes and see whether their network structure makes any difference. Overall, however, the quality of the data seems to be good/feasible since only a few cases contain missing data. Moreover, because the data covers almost all releases in the respective period, it is therefore comparable to similar websites like IMDB or MobyGames which have previously been studied to a great extent (Cattani \& Ferriani, 2008; De Vaan et al., 2015; Lutter, 2015).

The present study only focused on the board game industry and only on creative team performance. Nevertheless, we argue that the findings are somewhat transferable to other creative domains, because most creative industries are similar to each other in many regards (Menger, 1999). Nevertheless it should be noted that huge theoretical debate exists on whether creativity is something general or domain specific (Baer, 2010; Kaufman \& Baer, 2005). Even though much effort has gone into the understanding of creativity, we are not nearly at a point where it is fully understood/resolved from a scientific perspective. As others pointed out before, creativity is a complex area of research and further study is necessary to integrate findings in a multidimensional way (Feldman, 2009, p. 169). 


\section{References}

Accominotti, F. (2009). Creativity from Interaction: Artistic Movements and the Creativity Careers of Modern Painters. Poetics, 37(3), 267-294. https://doi.org/10.1016/j.poetic.2009.03.005

Baer, J. (2010). Is Creativity Domain Specific? In J. C. Kaufman \& R. J. Sternberg (Eds.), The Cambridge Handbook of Creativity. Cambridge University Press.

Bielby, W. T., \& Bielby, D. D. (1999). Organizational Mediation of Project-Based Labor Markets: Talent Agencies and the Careers of Screenwriters. American Sociological Review, 64(1), 65-85. https://doi.org/10.2307/2657278

Borgatti, S. P. (2009). Social Network Analysis, Two-Mode Concepts in. In R. A. Meyers (Ed.), Encyclopedia of Complexity and Systems Science (pp. 8279-8291). Springer New York. https://doi.org/10.1007/978-0-387-30440-3_491

Borgatti, S. P., \& Everett, M. G. (1997). Network Analysis of 2-Mode Data. Social Networks, 19(3), 243-269. https://doi.org/10.1016/S0378-8733(96)00301-2

Borgatti, S. P., \& Everett, M. G. (2000). Models of Core/Periphery Structures. Social Networks, 21(4), 375-395. https://doi.org/10.1016/S0378-8733(99)00019-2

Borgatti, S. P., \& Halgin, D. S. (2014). Analyzing Affiliation Networks. In J. Scott \& P. Carrington (Eds.), The SAGE Handbook of Social Network Analysis. SAGE Publications Ltd. https://doi.org/10.4135/9781446294413

Burt, R. S. (1992). Structural Holes. The Social Structure of Competition. Harvard University Press.

Burt, R. S. (2004). Structural Holes and Good Ideas. American Journal of Sociology, 110(2), 349-399. https://doi.org/10.1086/421787

Cattani, G., \& Ferriani, S. (2008). A Core/Periphery Perspective on Individual Creative Performance: Social Networks and Cinematic Achievements in the Hollywood Film Industry. Organization Science, 19(6), 824-844.

https://doi.org/10.1287/orsc.1070.0350

Csikszentmihalyi, M. (1996). Flow: Creativity and the Psychology of Discovery and Invention. Harper Perennial.

Csikszentmihalyi, M. (2009). Implications of a Systems Perspective for the Study of Creativity. Handbook of Creativity. Cambridge University Press.

De Vaan, M., Stark, D., \& Vedres, B. (2015). Game Changer: The Topology of Creativity. American Journal of Sociology, 120(4), 1144-1194. https://doi.org/10.1086/681213

Durkheim, E. (1912). The Elementary Forms of the Religious Life. Free Press. 
Faulkner, R. R., \& Anderson, A. B. (1987). Short-Term Projects and Emergent Careers: Evidence from Hollywood. American Journal of Sociology, 92(4), 879-909.

https://doi.org/10.1086/228586

Feldman, D. H. (2009). The Development of Creativity. In R. J. Sternberg (Ed.), Handbook of Creativity (12th ed.). Cambridge University Press.

Gilson, L. L., \& Shalley, C. E. (2004). A Little Creativity Goes a Long Way: An Examination of Teams' Engagement in Creative Processes. Journal of Management, 30(4), 453-470. https://doi.org/10.1016/j.jm.2003.07.001

Granovetter, M. (1983). The Strength of Weak Ties: A Network Theory Revisited. Sociological Theory, 1, 201-233.

Granovetter, M. S. (1985). Economic Action and Social Structure: The Problem of Embeddedness. American Journal of Sociology, 91(3), 481-510.

Guimerà, R., Brian, U., Spiro, J., \& Amaral, L. A. N. (2005). Team Assembly Mechanisms Determine Collaboration Network Structure and Team Performance. Science, 308, 697702. https://doi.org/10.1126/science.1106340

Hogg, M. A., \& Terry, D. J. (2000). Social Identity and Self-Categorization Processes in Organizational Contexts. The Academy of Management Review, 25(1), 121-140.

Hornsey, M. J., \& Hogg, M. A. (2000). Assimilation and Diversity: An Integrative Model of Subgroup Relations. Personality and Social Psychology Review, 4(2), 143-156.

https://doi.org/10.1207/s15327957pspr0402_03

Jensen, M., \& Kim, H. (2020). Reaching for the stars: The importance of reputational rank in creative career development. Poetics, 80, 101396.

https://doi.org/10.1016/j.poetic.2019.101396

Kaufman, J. C., \& Baer, J. (Eds.). (2005). Creativity Across Domains: Faces of the Muse. Erlbaum.

Lutter, M. (2014). Creative Success and Network Embeddedness: Explaining Critical Recognition of Film Directors in Hollywood, 1900-2010 (Discussion Paper No. 14/11). Max Planck Institute for the Study of Societies. https://www.econstor.eu/handle/10419/98923

Lutter, M. (2015). Do Women Suffer from Network Closure? The Moderating Effect of Social Capital on Gender Inequality in a Project-Based Labor Market, 1929 to 2010. American Sociological Review, 80(2), 329-358. https://doi.org/10.1177/0003122414568788

March, J. G. (1991). Exploration and Exploitation in Organizational Learning. Organization Science, 2(1), 71-87. https://doi.org/10.1287/orsc.2.1.71 
Menger, P.-M. (1999). Artistic Labor Markets and Careers. Annual Review of Sociology, 25, 541-574. https://doi.org/10.1146/annurev.soc.25.1.541

Mizruchi, M. S. (1996). What Do Interlocks Do? An Analysis, Critique, and Assessment of Research on Interlocking Directorates. Annual Review of Sociology, 22(1), 271-298. https://doi.org/10.1146/annurev.soc.22.1.271

Montoya, R. M., \& Horton, R. S. (2013). A Meta-Analytic Investigation of the Processes Underlying the Similarity-Attraction Effect. Journal of Social and Personal Relationships, 30(1), 64-94. https://doi.org/10.1177/0265407512452989

Opsahl, T. (2013). Triadic closure in two-mode networks: Redefining the global and local clustering coefficients. Social Networks, 35(2), 159-167.

https://doi.org/10.1016/j.socnet.2011.07.001

Perretti, F., \& Negro, G. (2006). Filling Empty Seats: How Status and Organizational Hierarchies Affect Exploration Versus Exploitation in Team Design. Academy of Management Journal, 49(4), 759-777. https://doi.org/10.2307/20159797

Perretti, F., \& Negro, G. (2007). Mixing Genres and Matching People: A Study in Innovation and Team Composition in Hollywood. Journal of Organizational Behavior, 28(5), 563-586. https://doi.org/10.1002/job.464

Perry-Smith, J. E. (2006). Social Yet Creative: The Role of Social Relationships in Facilitating Individual Creativity. Academy of Management Journal, 49(1), 85-101. https://doi.org/10.2307/20159747

Perry-Smith, J. E., \& Shalley, C. E. (2003). The Social Side of Creativity: A Static and Dynamic Social Network Perspective. Academy of Management Review, 28(1), 89-106. https://doi.org/10.2307/30040691

Quińones, M. A., Ford, J. K., \& Teachout, M. S. (1995). The Relationship Between Work Experience and Job Performance: A Conceptual and Meta-Analytic Review. Personnel Psychology, 48(4), 887-910. https://doi.org/10.1111/j.1744-6570.1995.tb01785.x

Rossman, G., Esparza, N., \& Bonacich, P. (2010). I'd Like to Thank the Academy, Team Spillovers, and Network Centrality. American Sociological Review, 75(1), 31-51. https://doi.org/10.1177/0003122409359164

Sawyer, K. R. (2010). Individual and Group Creativity. In J. C. Kaufman \& R. J. Sternberg (Eds.), The Cambridge Handbook of Creativity. Cambridge University Press.

Schmidt, F. L., \& Hunter, J. E. (1998). The Validity and Utility of Selection Methods in Personnel Psychology: Practical and Theoretical Implications of 85 Years of Research Findings. Psychological Bulletin, 124(2), 262-274. https://doi.org/10.1037//00332909.124.2.262

Seville, A. (2009). The sociable game of the goose. Proceedings of the Board Game Studies Colloquium XI, 1000-1014. 
Silver, D., Hubert, T., Schrittwieser, J., Antonoglou, I., Lai, M., Guez, A., Lanctot, M., Sifre, L., Kumaran, D., Graepel, T., Lillicrap, T., Simonyan, K., \& Hassabis, D. (2018). A general reinforcement learning algorithm that masters chess, shogi, and Go through self-play. Science, 362(6419), 1140-1144. https://doi.org/10.1126/science.aar6404

Stark, D. (2009). The Sense of Dissonance: Accounts of Worth in Economic Life. Princeton University Press.

Uzzi, B., \& Spiro, J. (2005). Collaboration and Creativity: The Small World Problem. American Journal of Sociology, 111(2), 447-504. https://doi.org/10.1086/432782

Vedres, B., \& Stark, D. (2010). Structural Folds: Generative Disruption in Overlapping Groups. American Journal of Sociology, 115(4), 1150-1190.

https://doi.org/10.1086/649497

Wachs, J., \& Vedres, B. (2021). Does Crowdfunding Really Foster Innovation? Evidence from the Board Game Industry. arXiv preprint arXiv:2101.02683.

$<$ https://arxiv.org/abs/2101.02683>

Whitehill, B. (1999). American Games: A Historical Perspective. Board Game Studies, 2, 116-141.

Zagal, J. P., Rick, J., \& Hsi, I. (2006). Collaborative games: Lessons learned from board games. Simulation \& Gaming, 37(1), 24-40.

https://doi.org/10.1177/1046878105282279 
TABLES AND FIGURES

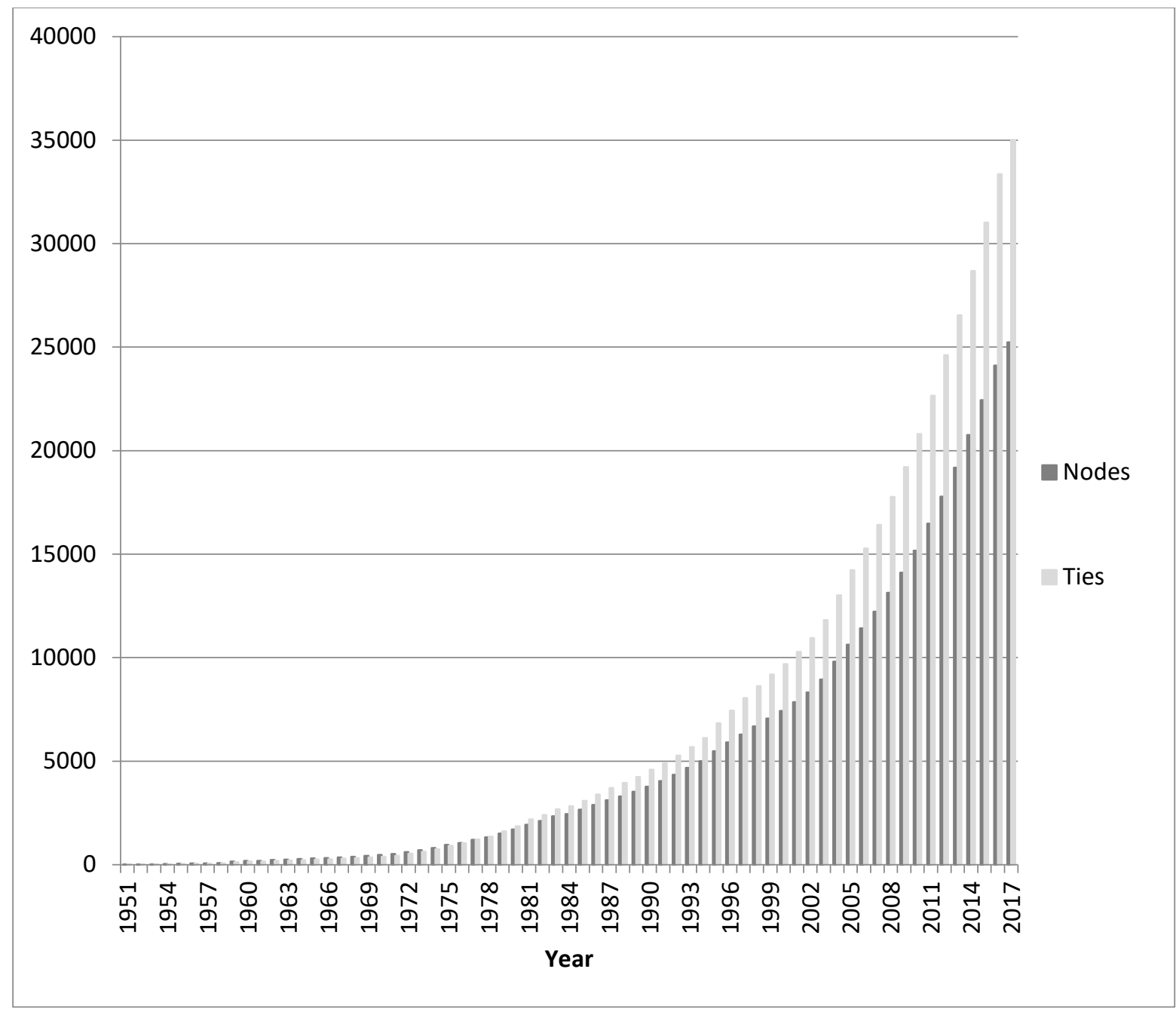

Figure 1: Distribution of nodes (games and developers) and ties (connections between nodes) in the present network (1951-2017).

Table 1: Descriptive statistics

\begin{tabular}{lrrrrr}
\hline Variables & $N$ & Mean & Std. Dev. & Min & Max \\
\hline Awards & 12,731 & 0.56 & 1.79 & 0 & 50 \\
Rating & 12,731 & 5731.1 & 400.05 & 4209 & 8496 \\
Betweenness centrality (t3) & 12,731 & 0.00034 & 0.00103 & 0 & 0.0241 \\
Newcomers & 12,731 & 0.34 & 0.39 & 0 & 1 \\
Experience & 12,731 & 11.22 & 22.06 & 0 & 303 \\
Teamsize & 12,731 & 2.75 & 3.42 & 1 & 107 \\
Reimplements & 12,731 & 0.099 & 0.30 & 0 & 1 \\
Difficulty & 12,539 & 2.101 & 0.81 & 1 & 5 \\
Time & 12,731 & 54.36 & 11.96 & 1 & 67 \\
\hline
\end{tabular}


Table 2: OLS Regressions on number of awards as dependent variable

\begin{tabular}{|c|c|c|c|c|c|c|}
\hline & $\begin{array}{c}(1) \\
\text { Awards }\end{array}$ & $\begin{array}{c}(2) \\
\text { Awards }\end{array}$ & $\begin{array}{c}\text { (3) } \\
\text { Awards }\end{array}$ & $\begin{array}{c}\text { (4) } \\
\text { Awards }\end{array}$ & $\begin{array}{c}\text { (5) } \\
\text { Awards }\end{array}$ & $\begin{array}{c}\text { (6) } \\
\text { Awards (ln) }\end{array}$ \\
\hline Betweenness centrality ( $t 3$ ) & $\begin{array}{l}358.4^{* * *} \\
(13.45)\end{array}$ & & $\begin{array}{c}273.2^{* * *} \\
(9.83)\end{array}$ & & $\begin{array}{c}257.2^{* * *} \\
(9.13)\end{array}$ & $\begin{array}{l}79.61^{* * *} \\
(10.04)\end{array}$ \\
\hline Betweenness centrality ( $t 3$ ) squared & $\begin{array}{c}-19624.0^{* * *} \\
(-9.65)\end{array}$ & & $\begin{array}{c}-15257.4^{* * *} \\
(-7.35)\end{array}$ & & $\begin{array}{c}-14461.5^{* * *} \\
(-6.92)\end{array}$ & $\begin{array}{c}-4342.2^{* * *} \\
(-7.39)\end{array}$ \\
\hline Newcomers & & $\begin{array}{c}-0.305^{* * *} \\
(-7.52)\end{array}$ & & $\begin{array}{c}-0.220^{* * *} \\
(-5.05)\end{array}$ & $\begin{array}{c}-0.151^{* * *} \\
(-3.44)\end{array}$ & $\begin{array}{c}-0.0414^{* * *} \\
(-3.34)\end{array}$ \\
\hline Experience & & & $\begin{array}{l}0.00401^{* * *} \\
\quad(5.38)\end{array}$ & $\begin{array}{c}0.00426^{* * *} \\
\quad(5.52)\end{array}$ & $\begin{array}{c}0.00326^{* * *} \\
(4.20)\end{array}$ & $\begin{array}{c}0.00196^{* * *} \\
(8.95)\end{array}$ \\
\hline Teamsize & & & $\begin{array}{c}0.0360^{* * *} \\
(7.61)\end{array}$ & $\begin{array}{c}0.0454^{* * *} \\
(9.73)\end{array}$ & $\begin{array}{c}0.0371^{* * *} \\
(7.82)\end{array}$ & $\begin{array}{c}0.0132^{* * *} \\
(9.88)\end{array}$ \\
\hline Reimplements & & & $\begin{array}{c}0.00914 \\
(0.17)\end{array}$ & $\begin{array}{c}-0.00778 \\
(-0.14)\end{array}$ & $\begin{array}{c}-0.0119 \\
(-0.22)\end{array}$ & $\begin{array}{c}-0.00215 \\
(-0.14)\end{array}$ \\
\hline Difficulty & & & $\begin{array}{c}0.134^{* * *} \\
(6.66)\end{array}$ & $\begin{array}{c}0.141^{* * *} \\
(6.97)\end{array}$ & $\begin{array}{c}0.133^{* * *} \\
(6.59)\end{array}$ & $\begin{array}{c}0.0422^{* * *} \\
(7.45)\end{array}$ \\
\hline Time (ln) & $\begin{array}{c}0.428^{* * *} \\
(8.07)\end{array}$ & $\begin{array}{c}0.283^{* * *} \\
(5.34)\end{array}$ & $\begin{array}{c}0.411^{* * *} \\
(7.61)\end{array}$ & $\begin{array}{c}0.303^{* * *} \\
(5.66)\end{array}$ & $\begin{array}{c}0.389^{* * *} \\
(7.16)\end{array}$ & $\begin{array}{c}0.104^{* * *} \\
(6.81)\end{array}$ \\
\hline Constant & $\begin{array}{c}-1.235^{* * *} \\
(-5.84) \\
\end{array}$ & $\begin{array}{l}-0.459^{*} \\
(-2.16)\end{array}$ & $\begin{array}{c}-1.563^{* * *} \\
(-7.09) \\
\end{array}$ & $\begin{array}{c}-1.027^{* * *} \\
(-4.64)\end{array}$ & $\begin{array}{c}-1.410^{* * *} \\
(-6.27)\end{array}$ & $\begin{array}{c}-0.323^{* * *} \\
(-5.11)\end{array}$ \\
\hline$R^{2}$ (adjusted) & 0.0172 & 0.00731 & 0.0286 & 0.0230 & 0.0294 & 0.0448 \\
\hline$F$ & 75.24 & 47.84 & 53.65 & 50.19 & 48.46 & 74.56 \\
\hline RMSE & 1.778 & 1.786 & 1.779 & 1.784 & 1.778 & 0.501 \\
\hline$N$ & 12731 & 12731 & 12539 & 12539 & 12539 & 12539 \\
\hline
\end{tabular}

Table 3: OLS Regressions on user rating as dependent variable

\begin{tabular}{|c|c|c|c|c|c|c|}
\hline & $\begin{array}{c}\text { (1) } \\
\text { Rating }\end{array}$ & $\begin{array}{c}(2) \\
\text { Rating }\end{array}$ & $\begin{array}{c}\text { (3) } \\
\text { Rating }\end{array}$ & $\begin{array}{c}\text { (4) } \\
\text { Rating }\end{array}$ & $\begin{array}{c}\text { (5) } \\
\text { Rating } \\
\end{array}$ & $\begin{array}{c}\text { (6) } \\
\text { Rating (In) }\end{array}$ \\
\hline Betweenness centrality (t3) & $\begin{array}{c}114178.8^{* * * *} \\
(19.62)\end{array}$ & & $\begin{array}{c}76134.2^{* * *} \\
(13.22)\end{array}$ & & $\begin{array}{c}71324.5^{* * *} \\
(12.23)\end{array}$ & $\begin{array}{l}11.66^{* * *} \\
(12.41)\end{array}$ \\
\hline Betweenness centrality ( $t 3$ ) squared & $\begin{array}{c}-5866194.0^{* * *} \\
(-13.20)\end{array}$ & & $\begin{array}{c}-3926463.2^{* * *} \\
(-9.13)\end{array}$ & & $\begin{array}{c}-3686841.8^{* * *} \\
(-8.53)\end{array}$ & $\begin{array}{c}-601.4^{* * *} \\
(-8.63)\end{array}$ \\
\hline Newcomers & & $\begin{array}{c}-104.1^{* * *} \\
(-11.71)\end{array}$ & & $\begin{array}{c}-65.08^{* * *} \\
(-7.20)\end{array}$ & $\begin{array}{c}-45.55^{* * *} \\
(-5.00)\end{array}$ & $\begin{array}{c}-0.00749^{* * *} \\
(-5.10)\end{array}$ \\
\hline Experience & & & $\begin{array}{l}0.414^{* *} \\
(2.68)\end{array}$ & $\begin{array}{l}0.474^{* *} \\
(2.95)\end{array}$ & $\begin{array}{l}0.188 \\
(1.17)\end{array}$ & $\begin{array}{c}0.0000378 \\
(1.46)\end{array}$ \\
\hline Teamsize & & & $\begin{array}{l}13.29^{* * *} \\
(13.55)\end{array}$ & $\begin{array}{l}15.95^{* * *} \\
(16.46)\end{array}$ & $\begin{array}{l}13.60^{* * *} \\
(13.85)\end{array}$ & $\begin{array}{c}0.00220^{* * *} \\
(13.93)\end{array}$ \\
\hline Reimplements & & & $\begin{array}{l}156.5^{* * *} \\
(14.05)\end{array}$ & $\begin{array}{l}151.3^{* * *} \\
(13.42)\end{array}$ & $\begin{array}{l}150.2^{* * *} \\
(13.41)\end{array}$ & $\begin{array}{c}0.0248^{* * *} \\
(13.74)\end{array}$ \\
\hline Difficulty & & & $\begin{array}{l}129.3^{* * *} \\
(31.01)\end{array}$ & $\begin{array}{l}131.2^{* * *} \\
(31.33)\end{array}$ & $\begin{array}{l}128.8^{* * *} \\
(30.93)\end{array}$ & $\begin{array}{c}0.0212^{* * *} \\
(31.61)\end{array}$ \\
\hline Time (ln) & $\begin{array}{l}255.1^{* * * *} \\
(22.04)\end{array}$ & $\begin{array}{c}206.6^{* * *} \\
(17.74)\end{array}$ & $\begin{array}{c}253.5^{* * *} \\
(22.65)\end{array}$ & $\begin{array}{c}221.9^{* * *} \\
(19.93)\end{array}$ & $\begin{array}{c}246.9^{* * *} \\
(21.94)\end{array}$ & $\begin{array}{c}0.0414^{* * *} \\
(22.83)\end{array}$ \\
\hline Constant & $\begin{array}{c}4688.9^{* * *} \\
(101.46)\end{array}$ & $\begin{array}{c}4948.6^{* * *} \\
(105.95)\end{array}$ & $\begin{array}{c}4380.5^{* * *} \\
(95.83)\end{array}$ & $\begin{array}{c}4538.0^{* * *} \\
(98.68) \\
\end{array}$ & $\begin{array}{c}4426.7^{* * *} \\
(95.01) \\
\end{array}$ & $\begin{array}{c}8.434^{* * *} \\
(1122.90) \\
\end{array}$ \\
\hline$R^{2}$ (adjusted) & 0.0579 & 0.0381 & 0.161 & 0.152 & 0.162 & 0.169 \\
\hline$F$ & 261.9 & 253.1 & 343.8 & 375.1 & 304.5 & 319.7 \\
\hline RMSE & 388.3 & 392.4 & 368.6 & 370.5 & 368.3 & 0.0594 \\
\hline$N$ & 12731 & 12731 & 12539 & 12539 & 12539 & 12539 \\
\hline
\end{tabular}

Notes: $t$ statistics in parentheses; ${ }^{+} p<0.1,{ }^{*} p<0.05,{ }^{* *} p<0.01,{ }^{* * *} p<0.001$ 

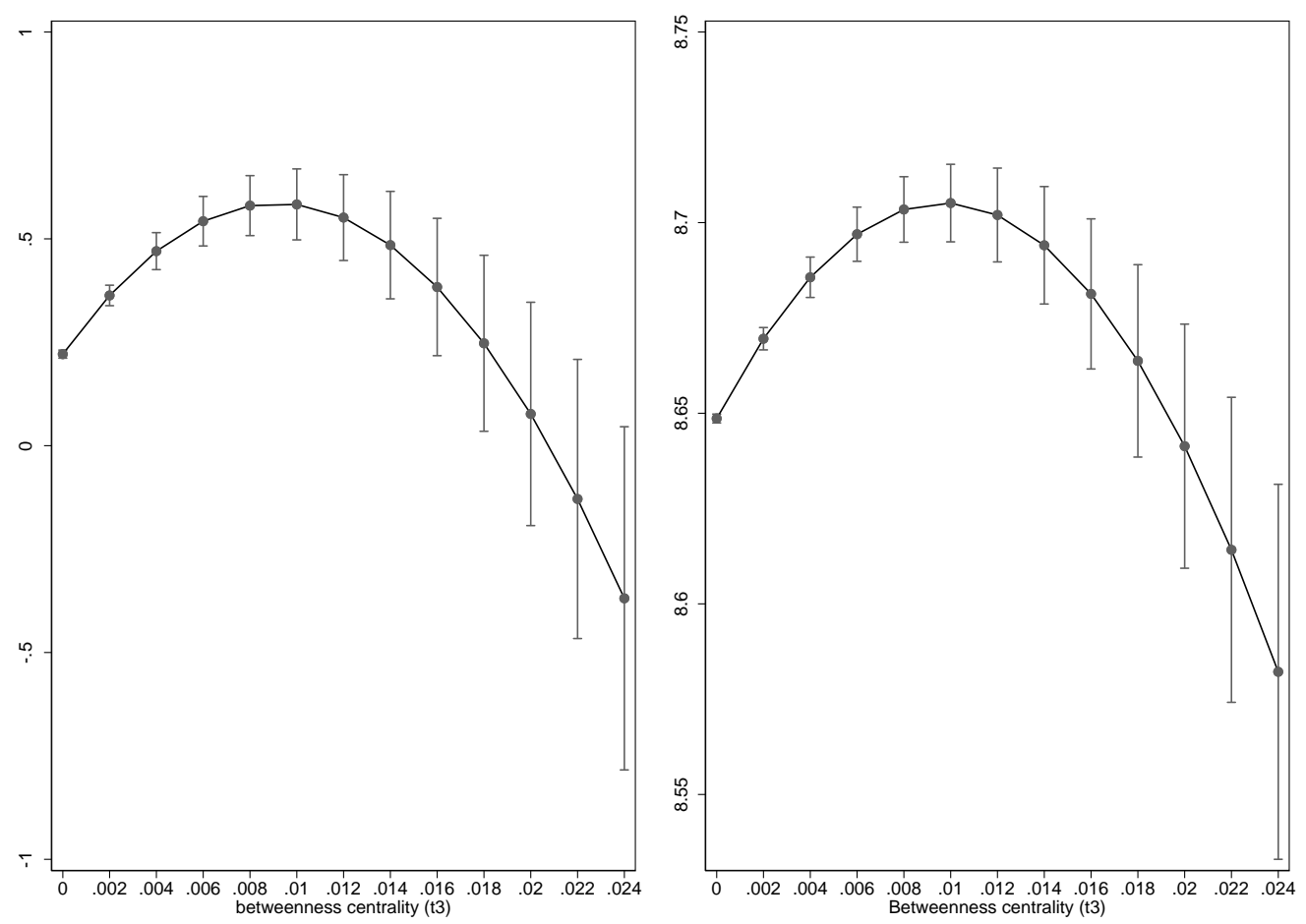

Figure 2: Graphical representation of the nonlinear betweenness effect for awards (left panel) and rating (right panel), based on Model 6 in Tables 2 and 3 
Table 4: Alternative specifications

\begin{tabular}{|c|c|c|c|c|c|}
\hline & $\begin{array}{c}1) \\
\text { Logit Model DV: } \\
\text { Awards dummy }\end{array}$ & $\begin{array}{c}(2) \\
\text { Logit Model DV: } \\
\text { Top-25\%-Rating }\end{array}$ & $\begin{array}{c}\text { (3) } \\
\text { Logit Model DV: } \\
\text { Top-10\%-Rating }\end{array}$ & $\begin{array}{c}\text { (4) } \\
\text { OLS: } \\
\text { Awards }\end{array}$ & $\begin{array}{c}\text { (5) } \\
\text { OLS: } \\
\text { Rating }\end{array}$ \\
\hline Betweenness centrality (t3) & $\begin{array}{c}289.1^{* * * *} \\
(7.49)\end{array}$ & $\begin{array}{c}239.0^{* * * *} \\
(6.24)\end{array}$ & $\begin{array}{c}623.4^{* * * *} \\
(9.83)\end{array}$ & $\begin{array}{l}90.03^{* * *} \\
(5.10)\end{array}$ & $\begin{array}{l}22632.9^{* * * *} \\
(6.19)\end{array}$ \\
\hline Betweenness centrality (t3) squared & $\begin{array}{c}-18209.6^{* * *} \\
(-4.69)\end{array}$ & $\begin{array}{c}-14138.3^{* * *} \\
(-4.73)\end{array}$ & $\begin{array}{c}-47942.8^{* * *} \\
(-5.37)\end{array}$ & & \\
\hline Newcomers & $\begin{array}{l}-0.205^{* *} \\
(-3.23)\end{array}$ & $\begin{array}{c}-0.238^{* * *} \\
(-4.39)\end{array}$ & $\begin{array}{c}-0.509^{* * *} \\
(-5.07)\end{array}$ & $\begin{array}{c}-0.190^{* * *} \\
(-4.29)\end{array}$ & $\begin{array}{c}-59.94^{* * *} \\
(-6.55)\end{array}$ \\
\hline Experience & $\begin{array}{l}0.00916^{* * *} \\
(9.79)\end{array}$ & $\begin{array}{l}0.00589^{* * *} \\
\quad(5.62)\end{array}$ & $\begin{array}{c}-0.00249^{+} \\
(-1.85)\end{array}$ & $\begin{array}{l}0.00377^{* * *} \\
(4.86)\end{array}$ & $\begin{array}{l}0.338^{*} \\
(2.10)\end{array}$ \\
\hline Teamsize & $\begin{array}{l}0.0502^{* * *} \\
(6.54)\end{array}$ & $\begin{array}{l}0.143^{* * *} \\
(11.11)\end{array}$ & $\begin{array}{l}0.0691^{* * *} \\
(7.47)\end{array}$ & $\begin{array}{l}0.0409^{* * *} \\
(8.55)\end{array}$ & $\begin{array}{l}13.87^{* * *} \\
(13.98)\end{array}$ \\
\hline Reimplements & $\begin{array}{l}-0.0165 \\
(-0.23)\end{array}$ & $\begin{array}{l}0.824^{* * *} \\
(11.58)\end{array}$ & $\begin{array}{l}0.667^{* * *} \\
(7.91)\end{array}$ & $\begin{array}{c}-0.00816 \\
(-0.15)\end{array}$ & $\begin{array}{l}151.0^{* * *} \\
(13.46)\end{array}$ \\
\hline Difficulty & $\begin{array}{l}0.170^{* * *} \\
(6.31)\end{array}$ & $\begin{array}{l}0.776^{* * *} \\
(29.08)\end{array}$ & $\begin{array}{l}0.743^{* * *} \\
(19.53)\end{array}$ & $\begin{array}{l}0.136^{* * *} \\
(6.73)\end{array}$ & $\begin{array}{l}129.6^{* * *} \\
(31.07)\end{array}$ \\
\hline $\begin{array}{l}\text { Betweenness centrality }(t 3) * \\
\text { Newcomers }\end{array}$ & & & & $\begin{array}{l}63.11 \\
(0.82)\end{array}$ & $\begin{array}{c}77371.8^{* * *} \\
(4.87)\end{array}$ \\
\hline Time (In) & $\begin{array}{l}0.323^{* * *} \\
(3.91)\end{array}$ & $\begin{array}{l}1.637^{* * *} \\
(19.69)\end{array}$ & $\begin{array}{l}3.057^{* * *} \\
(15.24)\end{array}$ & $\begin{array}{c}0.364^{* * *} \\
(6.60)\end{array}$ & $\begin{array}{l}248.2^{* * *} \\
(21.75)\end{array}$ \\
\hline Constant & $\begin{array}{c}-3.150^{* * *} \\
(-9.20)\end{array}$ & $\begin{array}{l}-8.584^{* * *} \\
(-24.63)\end{array}$ & $\begin{array}{l}-16.51^{* * *} \\
(-19.67)\end{array}$ & $\begin{array}{c}-1.282^{* * *} \\
(-5.65)\end{array}$ & $\begin{array}{l}4430.7^{* * *} \\
(94.21)\end{array}$ \\
\hline$R^{2}$ (McFadden) & 0.1268 & 0.1268 & 0.1332 & & \\
\hline $\begin{array}{l}R^{2} \text { (adjusted) } \\
F\end{array}$ & & & & $\begin{array}{c}0.0257 \\
42.39\end{array}$ & $\begin{array}{l}0.159 \\
297.2\end{array}$ \\
\hline RMSE & & & & 1.782 & 369.0 \\
\hline$N$ & 12539 & 12539 & 12539 & 12539 & 12539 \\
\hline
\end{tabular}



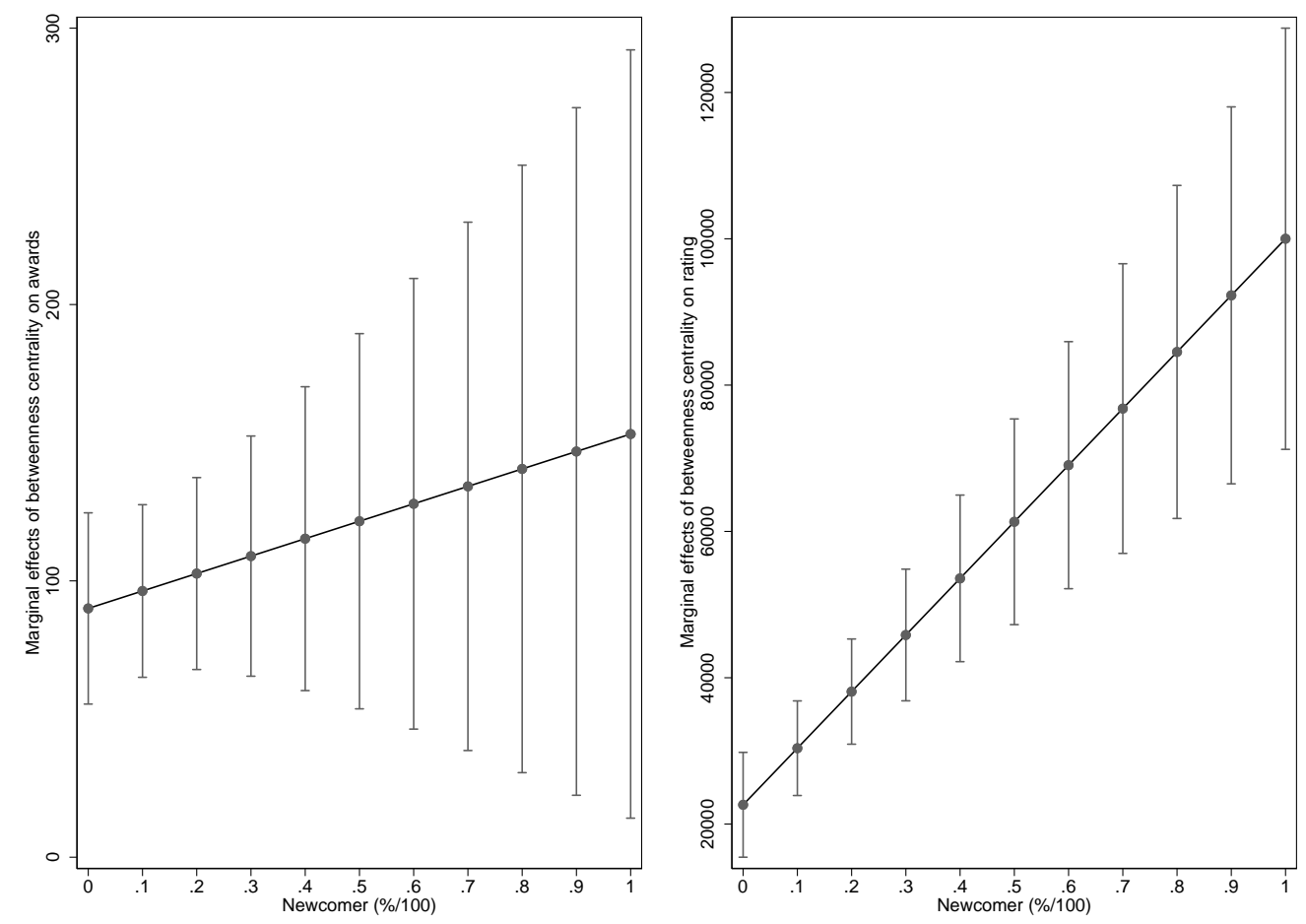

Figure 3: Visualization of the interaction effects between the newcomer variable and betweenness centrality; shown are marginal effects of betweenness centrality on awards (left panel) and rating (right panel), conditional on the share of newcomers per team, estimated with 95\% confidence intervals; based on Model 4 (left panel) and Model 5 (right panel) of Table 4 


\section{APPENDIX}

Table A1: Correlation matrix of all variables used in this study

\begin{tabular}{|c|c|c|c|c|c|c|c|c|c|}
\hline & Awards & Rating & $\begin{array}{l}\text { Between- } \\
\text { ness cen- } \\
\text { trality (t3) }\end{array}$ & $\begin{array}{l}\text { New- } \\
\text { comer }\end{array}$ & $\begin{array}{l}\text { Exp- } \\
\text { erience }\end{array}$ & Teamsize & $\begin{array}{l}\text { Reimp- } \\
\text { lements }\end{array}$ & Difficulty & Time (ln) \\
\hline Awards & 1 & & & & & & & & \\
\hline Rating & 0.5783 & 1 & & & & & & & \\
\hline $\begin{array}{l}\text { Betweenness } \\
\text { centrality (t3) }\end{array}$ & 0.0759 & 0.1068 & 1 & & & & & & \\
\hline Newcomer & -0.0724 & -0.1204 & -0.1551 & 1 & & & & & \\
\hline Experience & 0.0783 & 0.1034 & 0.1500 & -0.3348 & 1 & & & & \\
\hline Teamsize & 0.0926 & 0.1732 & 0.1237 & 0.0282 & -0.0229 & 1 & & & \\
\hline Reimplements & 0.0206 & 0.1497 & 0.0247 & -0.1506 & 0.1071 & 0.0391 & 1 & & \\
\hline Difficulty & 0.0797 & 0.2778 & 0.0891 & -0.0609 & 0.133 & 0.12 & 0.0173 & 1 & \\
\hline Time (ln) & 0.0572 & 0.1708 & -0.1342 & -0.1145 & 0.0731 & 0.018 & 0.0911 & -0.0655 & 1 \\
\hline
\end{tabular}

Table A2: Variance Inflation Factors for Model 5 of Table 2

\begin{tabular}{lcc}
\hline & VIF & 1/VIF \\
\hline Betweenness centrality (t3) & 3.40 & 0.293744 \\
Betweenness centrality (t3) squared & 3.18 & 0.314781 \\
Newcomers & 1.19 & 0.841308 \\
Experience & 1.17 & 0.852005 \\
Teamsize & 1.06 & 0.944635 \\
Reimplements & 1.03 & 0.966568 \\
Difficulty & 1.04 & 0.958276 \\
Time (ln) & 1.06 & 0.940999 \\
\hline Mean VIF & 1.64 & \\
\hline
\end{tabular}


Tab. A3: Replication of main results using bootstrapped standard errors; Models 1-6: Replication of Table 2; Models 7-8: Replication of Models 5-6 of Table 3

\begin{tabular}{|c|c|c|c|c|c|c|c|c|}
\hline & $\begin{array}{c}(1) \\
\text { Awards }\end{array}$ & $\begin{array}{c}(2) \\
\text { Awards }\end{array}$ & $\begin{array}{c}\text { (3) } \\
\text { Awards }\end{array}$ & $\begin{array}{c}\text { (4) } \\
\text { Awards }\end{array}$ & $\begin{array}{c}\text { (5) } \\
\text { Awards }\end{array}$ & $\begin{array}{c}(6) \\
\text { Awards } \\
(\ln )\end{array}$ & $\begin{array}{c}\text { (7) } \\
\text { Rating }\end{array}$ & $\begin{array}{c}\text { (8) } \\
\text { Rating (ln) }\end{array}$ \\
\hline Betweenness centrality ( $t 3)$ & $\begin{array}{c}358.4^{* * *} \\
(8.90)\end{array}$ & & $\begin{array}{c}273.2^{* * *} \\
(6.63)\end{array}$ & & $\begin{array}{c}257.2^{* * *} \\
(6.36)\end{array}$ & $\begin{array}{c}79.61^{* * *} \\
(7.45)\end{array}$ & $\begin{array}{c}71324.5^{* * *} \\
(8.94)\end{array}$ & $\begin{array}{c}11.66^{* * *} \\
(9.03)\end{array}$ \\
\hline Betweenness centrality (t3) squared & $\begin{array}{c}-19624.0^{* * *} \\
(-5.35)\end{array}$ & & $\begin{array}{c}-15257.4^{* * *} \\
(-4.40)\end{array}$ & & $\begin{array}{c}-14461.5^{* * *} \\
(-4.32)\end{array}$ & $\begin{array}{c}-4342.2^{* * *} \\
(-4.26)\end{array}$ & $\begin{array}{c}-3686841.8^{* * * *} \\
(-5.48)\end{array}$ & $\begin{array}{c}-601.4^{* * *} \\
(-5.43)\end{array}$ \\
\hline Newcomers & & $\begin{array}{c}-0.305^{* * *} \\
(-9.97)\end{array}$ & & $\begin{array}{c}-0.220^{* * *} \\
(-6.64)\end{array}$ & $\begin{array}{c}-0.151^{* * *} \\
(-4.74)\end{array}$ & $\begin{array}{c}-0.0414^{* * *} \\
(-4.02)\end{array}$ & $\begin{array}{c}-45.55^{* * *} \\
(-6.14)\end{array}$ & $\begin{array}{c}-0.00749^{* * *} \\
(-6.15)\end{array}$ \\
\hline Experience & & & $\begin{array}{c}0.00401^{* * *} \\
(5.71)\end{array}$ & $\begin{array}{c}0.00426^{* * *} \\
\quad(5.81)\end{array}$ & $\begin{array}{c}0.00326^{* * *} \\
(4.37)\end{array}$ & $\begin{array}{l}0.00196^{* * *} \\
\quad(7.78)\end{array}$ & $\begin{array}{l}0.188 \\
(1.16)\end{array}$ & $\begin{array}{c}0.0000378 \\
(1.44)\end{array}$ \\
\hline Teamsize & & & $\begin{array}{c}0.0360^{* * *} \\
(4.62)\end{array}$ & $\begin{array}{c}0.0454^{* * *} \\
(5.56)\end{array}$ & $\begin{array}{c}0.0371^{* * *} \\
(4.72)\end{array}$ & $\begin{array}{c}0.0132^{* * *} \\
(5.99)\end{array}$ & $\begin{array}{c}13.60^{* * *} \\
(5.53)\end{array}$ & $\begin{array}{c}0.00220^{* * * *} \\
\quad(5.61)\end{array}$ \\
\hline Reimplements & & & $\begin{array}{c}0.00914 \\
(0.16)\end{array}$ & $\begin{array}{c}-0.00778 \\
(-0.13)\end{array}$ & $\begin{array}{c}-0.0119 \\
(-0.20)\end{array}$ & $\begin{array}{c}-0.00215 \\
(-0.13)\end{array}$ & $\begin{array}{l}150.2^{* * *} \\
(10.53)\end{array}$ & $\begin{array}{c}0.0248^{* * *} \\
(10.94)\end{array}$ \\
\hline Difficulty & & & $\begin{array}{c}0.134^{* * * *} \\
(6.11)\end{array}$ & $\begin{array}{c}0.141^{* * *} \\
(6.40)\end{array}$ & $\begin{array}{c}0.133^{* * *} \\
(6.07)\end{array}$ & $\begin{array}{c}0.0422^{* * *} \\
\quad(6.77)\end{array}$ & $\begin{array}{l}128.8^{* * *} \\
(25.97)\end{array}$ & $\begin{array}{c}0.0212^{* * *} \\
(27.05)\end{array}$ \\
\hline Time (ln) & $\begin{array}{l}0.428^{* * *} \\
(13.22)\end{array}$ & $\begin{array}{l}0.283^{* * *} \\
(10.86)\end{array}$ & $\begin{array}{l}0.411^{* * *} \\
(11.64)\end{array}$ & $\begin{array}{l}0.303^{* * *} \\
(10.55)\end{array}$ & $\begin{array}{c}0.389^{* * *} \\
(11.33)\end{array}$ & $\begin{array}{c}0.104^{* * *} \\
(9.89)\end{array}$ & $\begin{array}{l}246.9^{* * *} \\
(20.74)\end{array}$ & $\begin{array}{c}0.0414^{* * *} \\
(20.58)\end{array}$ \\
\hline Constant & $\begin{array}{c}-1.235^{* * *} \\
(-9.98)\end{array}$ & $\begin{array}{c}-0.459^{* * *} \\
(-4.84) \\
\end{array}$ & $\begin{array}{c}-1.563^{* * *} \\
(-10.34)\end{array}$ & $\begin{array}{c}-1.027^{* * *} \\
(-8.24)\end{array}$ & $\begin{array}{c}-1.410^{* * *} \\
(-9.71)\end{array}$ & $\begin{array}{c}-0.323^{* * *} \\
(-7.25)\end{array}$ & $\begin{array}{c}4426.7^{* * *} \\
(88.75)\end{array}$ & $\begin{array}{c}8.434^{* * *} \\
(1006.54)\end{array}$ \\
\hline $\begin{array}{l}R^{2} \text { (adjusted) } \\
R M S E \\
N\end{array}$ & $\begin{array}{c}0.0172 \\
1.778 \\
12731\end{array}$ & $\begin{array}{c}0.00731 \\
1.786 \\
12731\end{array}$ & $\begin{array}{c}0.0286 \\
1.779 \\
12539\end{array}$ & $\begin{array}{c}0.0230 \\
1.784 \\
12539\end{array}$ & $\begin{array}{c}0.0294 \\
1.778 \\
12539\end{array}$ & $\begin{array}{c}0.0448 \\
0.501 \\
12539\end{array}$ & $\begin{array}{l}0.162 \\
368.3 \\
12539\end{array}$ & $\begin{array}{c}0.169 \\
0.0594 \\
12539\end{array}$ \\
\hline
\end{tabular}

Notes: Bootstrapped standard errors (20000 replications); $t$ statistics in parentheses; ${ }^{+} p<0.1,{ }^{*} p<0.05$, ${ }^{* *} p<0.01,{ }^{* * *} p<0.001$ 
Tab. A4: Replication of main results (Models 5 of Table 2 and 3) using betweenness centrality with five- and ten-year windows (Models 1-4); using time dummies instead of logged time counter (Models 5-6)

\begin{tabular}{|c|c|c|c|c|c|c|}
\hline & $\begin{array}{c}(1) \\
\text { Awards }\end{array}$ & $\begin{array}{c}(2) \\
\text { Rating }\end{array}$ & $\begin{array}{c}(3) \\
\text { Awards }\end{array}$ & $\begin{array}{c}\text { (4) } \\
\text { Rating }\end{array}$ & $\begin{array}{c}\text { (5) } \\
\text { Awards }\end{array}$ & $\begin{array}{c}(6) \\
\text { Rating }\end{array}$ \\
\hline Betweenness centrality ( $(5)$ & $\begin{array}{c}150.8^{* * *} \\
(5.86)\end{array}$ & $\begin{array}{c}47351.6^{* * * *} \\
(8.87)\end{array}$ & & & & \\
\hline Betweenness centrality (t5) squared & $\begin{array}{c}-2829.9^{* * *} \\
(-4.26)\end{array}$ & $\begin{array}{c}-888863.7^{* * *} \\
(-6.45)\end{array}$ & & & & \\
\hline Betweenness centrality (t10) & & & $\begin{array}{c}241.2^{* * *} \\
(5.57)\end{array}$ & $\begin{array}{c}73468.5^{* * *} \\
(8.18)\end{array}$ & & \\
\hline Betweenness centrality (t10) squared & & & $\begin{array}{c}-13027.9^{* * *} \\
(-4.23)\end{array}$ & $\begin{array}{c}-3422041.5^{* * *} \\
(-5.35)\end{array}$ & & \\
\hline Betweenness centrality ( $t 3$ ) & & & & & $\begin{array}{c}269.2^{* * *} \\
(9.47)\end{array}$ & $\begin{array}{c}77746.8^{* * *} \\
(13.21)\end{array}$ \\
\hline Betweenness centrality (t3) squared & & & & & $\begin{array}{c}-14827.3^{* * *} \\
(-7.08)\end{array}$ & $\begin{array}{c}-3932060.0^{* * * *} \\
(-9.07)\end{array}$ \\
\hline Newcomers & $\begin{array}{c}-0.182^{* * *} \\
(-4.15)\end{array}$ & $\begin{array}{c}-53.32^{* * *} \\
(-5.86)\end{array}$ & $\begin{array}{c}-0.184^{* * *} \\
(-4.20)\end{array}$ & $\begin{array}{c}-53.93^{* * *} \\
(-5.92)\end{array}$ & $\begin{array}{c}-0.132^{* *} \\
(-3.01)\end{array}$ & $\begin{array}{c}-50.87^{* * *} \\
(-5.60)\end{array}$ \\
\hline Experience & $\begin{array}{c}0.00382^{* * * *} \\
(4.93)\end{array}$ & $\begin{array}{l}0.335^{*} \\
(2.09)\end{array}$ & $\begin{array}{c}0.00390^{* * *} \\
(5.04)\end{array}$ & $\begin{array}{l}0.362^{*} \\
(2.26)\end{array}$ & $\begin{array}{c}0.00286^{* * *} \\
(3.68)\end{array}$ & $\begin{array}{c}0.0642 \\
(0.40)\end{array}$ \\
\hline Teamsize & $\begin{array}{c}0.0409^{* * *} \\
(8.64)\end{array}$ & $\begin{array}{l}14.52^{* * *} \\
(14.82)\end{array}$ & $\begin{array}{c}0.0408^{* * *} \\
(8.62)\end{array}$ & $\begin{array}{l}14.54^{* * *} \\
(14.81)\end{array}$ & $\begin{array}{c}0.0359^{* * *} \\
(7.60)\end{array}$ & $\begin{array}{l}13.53^{* * *} \\
(13.83)\end{array}$ \\
\hline Reimplements & $\begin{array}{c}-0.00848 \\
(-0.16)\end{array}$ & $\begin{array}{l}151.0^{* * * *} \\
(13.44)\end{array}$ & $\begin{array}{c}-0.00899 \\
(-0.17)\end{array}$ & $\begin{array}{l}150.9^{* * * *} \\
(13.43)\end{array}$ & $\begin{array}{l}0.0150 \\
(0.28)\end{array}$ & $\begin{array}{l}140.5^{* * *} \\
(12.57)\end{array}$ \\
\hline Difficulty & $\begin{array}{c}0.136^{* * *} \\
(6.75)\end{array}$ & $\begin{array}{l}129.7^{* * *} \\
(31.06)\end{array}$ & $\begin{array}{c}0.136^{* * *} \\
(6.75)\end{array}$ & $\begin{array}{l}129.9^{* * *} \\
(31.08)\end{array}$ & $\begin{array}{c}0.164^{* * *} \\
(8.13)\end{array}$ & $\begin{array}{l}136.0^{* * * *} \\
(32.45)\end{array}$ \\
\hline Time (ln) & $\begin{array}{l}0.355^{* * * *} \\
(6.54)\end{array}$ & $\begin{array}{l}238.1^{* * * *} \\
(21.17)\end{array}$ & $\begin{array}{c}0.354^{* * *} \\
(6.51)\end{array}$ & $\begin{array}{c}238.2^{* * *} \\
(21.11)\end{array}$ & & \\
\hline Time dummies & no & no & no & no & yes & yes \\
\hline Constant & $\begin{array}{c}-1.254^{* * *} \\
(-5.59) \\
\end{array}$ & $\begin{array}{c}4466.5^{* * *} \\
(95.97) \\
\end{array}$ & $\begin{array}{c}-1.252^{* * *} \\
(-5.56) \\
\end{array}$ & $\begin{array}{c}4466.2^{* * * *} \\
(95.65) \\
\end{array}$ & $\begin{array}{l}-0.224 \\
(-0.18) \\
\end{array}$ & $\begin{array}{c}5184.5^{* * *} \\
(20.05) \\
\end{array}$ \\
\hline$R^{2}$ (adjusted) & 0.0255 & 0.157 & 0.0253 & 0.156 & 0.0452 & 0.175 \\
\hline$F$ & 42.07 & 293.0 & 41.61 & 291.4 & 9.137 & 37.49 \\
\hline RMSE & 1.782 & 369.4 & 1.782 & 369.5 & 1.764 & 365.4 \\
\hline$N$ & 12539 & 12539 & 12539 & 12539 & 12539 & 12539 \\
\hline
\end{tabular}


Appendix B: Detailed calculation of the betweenness centrality measure (all taken from Borgatti 2009, p. 8287):

Equation 1, betweenness centrality: Betweenness centrality refers to the sum of shares of shortest paths that pass through a given node. The betweenness of node $k$ in an ordinary graph is defined by equation 1 , where $g_{i j}$ is the number of geodesic paths from node $i$ to node $j$, and $g_{i k j}$ is the number of geodesic paths from $i$ to $j$ that pass through $k$ :

$$
b_{k}=\frac{1}{2} \sum_{i \neq k}^{n} \sum_{j \neq k, i}^{n} \frac{g_{i k j}}{g_{i j}}
$$

Equation 2, betweenness normalization: Equation 2 gives the maximums for nodes in each vertex set as a function of the vertex set sizes. In the equation, $x$ div $y$ refers to integer division of $x$ by $y$ and $x \bmod y$ refers to the remainder of an integer division of $x$ by $y$ :

$$
\begin{gathered}
b_{V_{1} \max }=\frac{1}{2}\left[n_{2}{ }^{2}(s+1)^{2}+n_{2}(s+1)(2 t-s-1)-t(2 s-t+3)\right] \\
s=\left(n_{1}-1\right) \operatorname{div} n_{2}, \quad t=\left(n_{1}-1\right) \bmod n_{2} \\
b_{V_{2} \max }=\frac{1}{2}\left[n_{1}{ }^{2}(p+1)^{2}+n_{1}(p+1)(2 r-p-1)-r(2 p-r+3)\right] \\
p=\left(n_{2}-1\right) \operatorname{div} n_{1}, \quad r=\left(n_{1}-1\right) \bmod n_{2}
\end{gathered}
$$

Given these maxima, we can normalize standard betweenness centrality for bipartite graphs by dividing by these maxima:

$$
\begin{aligned}
& b_{i}^{*}=\frac{b_{i}}{b_{V_{1} \max }}, \text { for } i \in V_{1}, \\
& b_{j}^{*}=\frac{b_{j}}{b_{V_{2} \max }}, \text { for } j \in V_{2},
\end{aligned}
$$

